\title{
Using Real Options to value the flexibility of Engineering Management decisions in Infrastructure Projects
}

\author{
Bonsang Koo ${ }^{1}$
}

Accepted February 1, 2013

\begin{abstract}
Determining on a particular construction method is typically decided in the initial phases of a project. However, changing conditions during actual construction may require a different method or technology to be employed. Providing an option for project managers to change construction provides flexibility that can increase value to the overall project. This research provides the ability to modify construction methods as a real option, which allows its value to be modeled. The research also formalizes a way to integrate a binomial lattice model with the Earned Value Method's $S$-curve. The integrated model provides a decision support tool that planners can use to determine whether to exercise the option depending on the status metrics provided by EVM.
\end{abstract}

Keywords: Real Options, Earned Value, Construction Methods, Risk Management

\section{INTRODUCTION}

Construction projects have inherent risks that exist throughout the planning, design, construction and O\&M phases of the project. In particular, risks during the construction phase of a project are difficult to predict beforehand, and thus project managers must be given the authority to deal with such risks flexibly.

One way of dealing with construction risks is to change or modify the method of construction technology initially planned for a specific type of work. Allowing the project manager to change to a different method that is cheaper or faster provides 'managerial flexibility' and thus ensures that the project is within budget and on time.

Enabling construction methods to be modified during the construction phase is in fact allowing project managers to delay the decision to choose a particular construction method in the upstream phases such as planning and design. That is, it provides project managers the option or the right to delay, postpone or switch a decision until more information is available to them. Such rights are referred to as 'real options.'

Several research exist that have adopted real options theory to evaluate the value of deferred or switched decisions of construction projects, with a focus on PPP (public private partnership) projects. [4], [6], [7]. However, most of this research has been focused on delaying decisions until revenues have shown the need to expand the scope of the project. In this research, we focus specifically on the construction phase of the project, and how decisions can be made based on the current status of the project. More specifically, we focus on modeling the 'right' of delaying or switching the decision making of construction methods during the construction phase as a real option. We use the binomial tree method, a method of real option analysis, to value the option of delaying the decision of the specific construction method so that contractors have more 'managerial flexibility' with which they can react to uncertainty risks occurring the actual construction phase.

Also we link the option valuation tree (OVT) with the outputs of the EVM. The option valuation tree provides when and what costs an option should be exercised, while EVM provide information as to the current status of the project. Thus, if a project has been delayed, a contractor may refer to the OVT to determine whether changing to a different construction method is a better strategy. The linking of the two models enables EVM to be better utilized as a decision support tool, as to a restrictive monitoring tool.

\section{LITERATURE REVIEW}

\section{A. Real Options Valuation}

A real option is a right without an obligation to take specific future actions depending on how uncertain

${ }^{1}$ Assistant Professor, Dept. of Civil Engineering, Seoul National University of Science and Technology, bonsang@seoultech.ac.kr 
conditions evolve [1]. A real options valuation (ROV) or real options analysis (ROA), as a discipline, extends from its application in corporate finance, to decision making under uncertainty in general, adapting the techniques developed for financial options to "real-life" decisions.

Real options analysis is often contrasted with more standard techniques of capital budgeting, such as discounted cash flow (DCF) analysis and net present value (NPV). DCF and NPV do not take in to account the "flexibility" to alter strategy in view of actual market realizations [5].

The flexibility here refers to the option to defer, expand, contract, abandon, or switch investment decisions of a project which cannot be modeled using DCF and NPV.

For example, DCF quantifies the present value by averaging the expected cash flows regardless of whether a project may fail during its progress. ROA, on the other hand, models the failing of the project as an option to defer or abandon the project, and thus in this case the profits of the project do not incur over a certain threshold.

\section{B. Real Options Valuation Approaches}

The Black-Scholes Model, Binomial Lattice Model, and the Finite Difference Method are the three primary methods for valuing real options. The Black-Scholes model was the first model available for modeling the value of financial options. The Binomial Lattice model, developed by Cox and Rubenstein (1979) uses a set of binomial lattice to value real options and has been used widely for real options. Thus, this research adopts the use of the binomial lattice model for valuing construction method selection options. Table 1 describes the stages defined by Copeland and Antikarov (2002) to develop a binomial lattice model for real options.

\section{Real options in planning and management of construction projects}

Several research has been performed in applying real options analysis for the strategic planning and management of construction projects. Ford et al. (2002) provided the basic framework for the possibility of using real options for valuing a project using real options and used a road project case example to show the value of flexibility. Zhao and Tseng (2003) showed how and expansion option can used to model the gradually extension of a parking garage, and how the foundations of the garage should be designed to incorporate future expansions. Qingbin et al. (2004) showed that increases in project costs due to quality guarantees can be decreased by setting up a quality guarantee option at the start of the project and executing the option at the end of the project if it is deemed required. Huang and Chou (2006) evaluated the MRG and project abandon rights of the government in a BOT project using the Black Scholes option valuation model.

These research have focused on the conditions at the end of the project and determining whether projects should be expanded or delayed if and when uncertainties in project revenues have decreased. The focus of our research is using options to allow flexibility based on changing conditions during the construction phase of the project.

TABLE I

MODEL VARIABLES

\begin{tabular}{c|l|l}
\hline Stage & \multicolumn{1}{|c|}{ Real Options } & \multicolumn{1}{c}{ Con. Method Options } \\
\hline Stage 1 & $\begin{array}{l}\text { Use DCF to calculate } \\
\text { present value. }\end{array}$ & $\begin{array}{l}\text { Use DCF to calculate project } \\
\text { cost. }\end{array}$ \\
\hline Stage 2 & $\begin{array}{l}\text { Model uncertainty as } \\
\text { volatility } \sigma^{2} .\end{array}$ & $\begin{array}{l}\text { Identify project risks, model } \\
\text { as variables in MCS to } \\
\text { calculate } \sigma^{2} .\end{array}$ \\
\hline Stage 3 & Create present value tree. & $\begin{array}{l}\text { Each tree made represents } \\
\text { construction periods. }\end{array}$ \\
\hline Stage 4 & $\begin{array}{l}\text { Convert event tree into } \\
\text { option valuation tree. }\end{array}$ & $\begin{array}{l}\mathrm{K} \text { is switching cost. } \\
\mathrm{C} \text { is value of switching. }\end{array}$ \\
\hline
\end{tabular}

\section{ADOPTION FRAMEWORK CONSTRUCTION METHOD REAL OPTIONS AND THE EARNED VALUE METHOD}

\section{A. Modeling Construction Method Selection as a Real Option}

The first stage of this research required formalizing how the value of delaying or switching a construction method can be modeled as a real option. As shown in Table 2, we define two construction methods which have a tradeoff of cost and time between them. That is, construction method B is cheaper than A but also takes longer than A. In a typical project delivery method, the project manager selects either one of the two methods.

TABLE II

\begin{tabular}{c|c|c}
\multicolumn{3}{|c}{ SAMPLE CONSTRUCTION METHODS } \\
\hline Type & CM A & CM B \\
\hline Cost & 200 million won & 150 million won \\
\hline Duration & 40 days & 60 days \\
\hline
\end{tabular}

For example, construction method $\mathrm{A}$ is selected if the owner requires a compressed schedule. In the option scenario, the project manager has the option of delaying this decision until actual construction has started and can base the decision depending on whether the project is behind or ahead of schedule. Thus, as shown in the following pseudo code, the project manager can first select method $\mathrm{B}$, the cheaper method, and have an option to change or switch to the more expensive method $\mathrm{A}$, if and when the project is behind schedule. If the project is not behind schedule (i.e., on time) then the project manager does not have to execute the option.

Option: switch from construction method B to construction method A

if (planned duration $<$ actual duration) then \{exercise option\}

else \{option expires\} 
Figure 1 compares how this option can be modeled as a switching option in relation to a traditional real option. Table 1 shows how the individual steps for developing a binomial lattice model is modified to develop the lattices in the context of the 'construction method switching option.' Figure 2 shows a sample option tree developed using the defined steps.

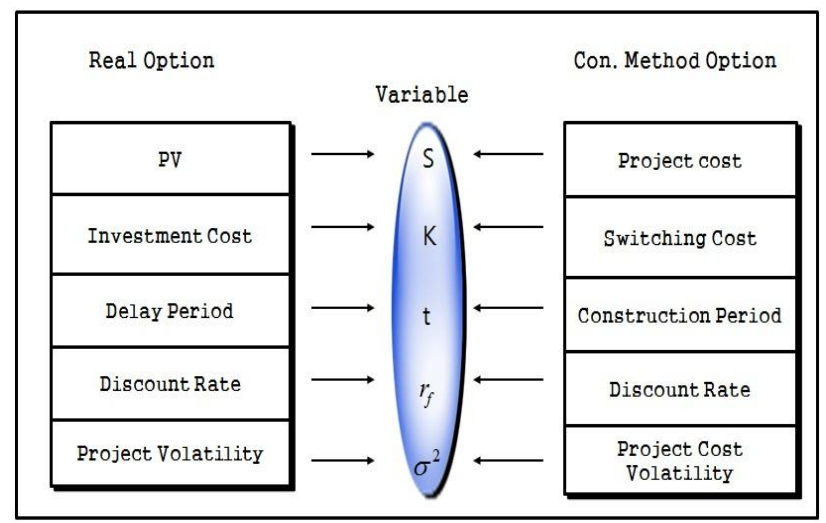

FIGURE I

VARIABLES FOR REAL OPTIONS AND CON. METHOD
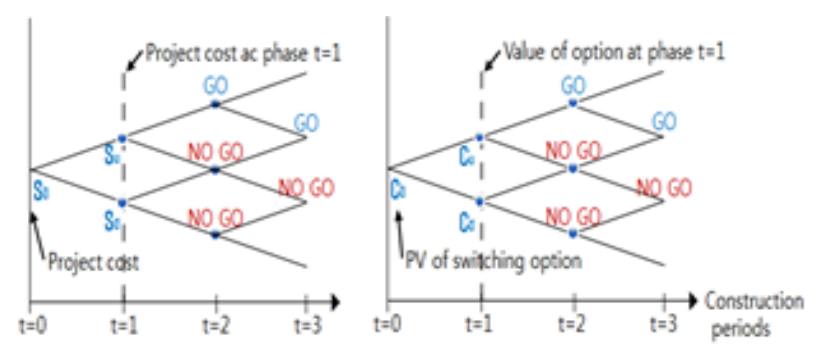

FIGURE II

SAMPLE Option VALUATION TREE

\section{B. Integrating the Binomial Lattice Model with Earned Value Method}

The second stage of this research involved formalizing a way to integrate the binomial lattices developed in the first stage with the S-curves and its metrics of the Earned Value method (EVM. As shown in Figure 3, EVM provides the status of the project in terms of cost $(\mathrm{CV})$ and time (SV), whereas the binomial lattices provides in monetary terms the value of switching from one method to another. Thus, this provides a way for project managers to decide on whether to change a method (i.e., execute the option) depending on the status of the project. This is expressed in the following pseudo code:

Option: switch from construction method $\mathrm{B}$ to construction method A

$$
\begin{aligned}
& \text { if }(\mathrm{SV}>\mathrm{C} 1) \text { then } \\
& \quad\{\text { exercise option } \\
& \text { else } \quad\{\text { option expires }
\end{aligned}
$$

Figure 4 shows that options can be developed for each of the major construction phases of the project, each having different construction methods. Thus, the model provides not one but several options that may or not be executed based on the changing conditions of the project. This provides several buffers with which a project manager may steer the project back on schedule, providing him with the required flexibility to mitigate unforeseen risks during the construction phase of the project.

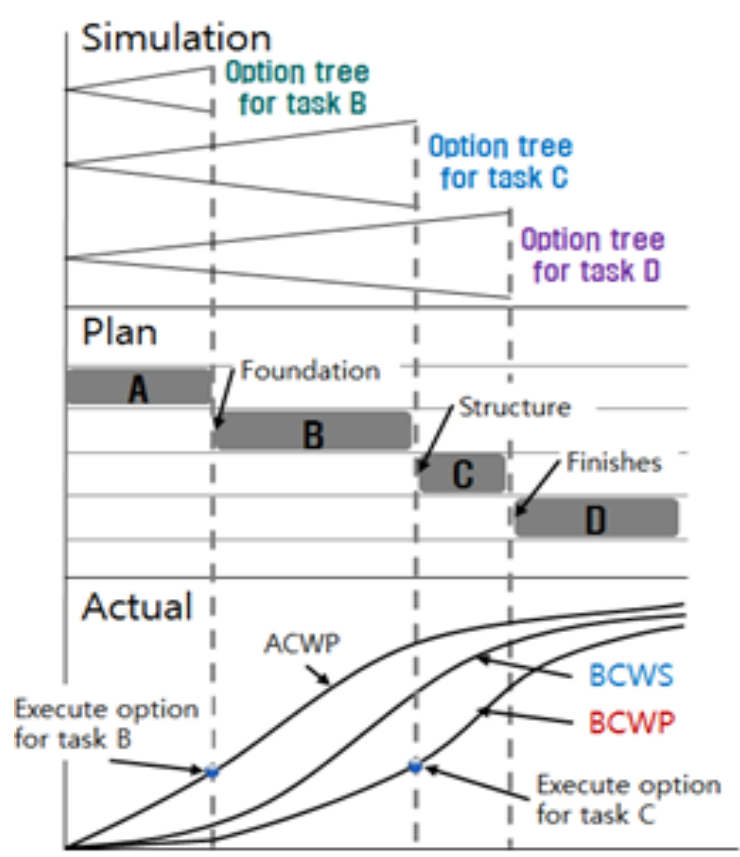

FIGURE III

LINKING BINOMIAL LATTICE WITH EVM

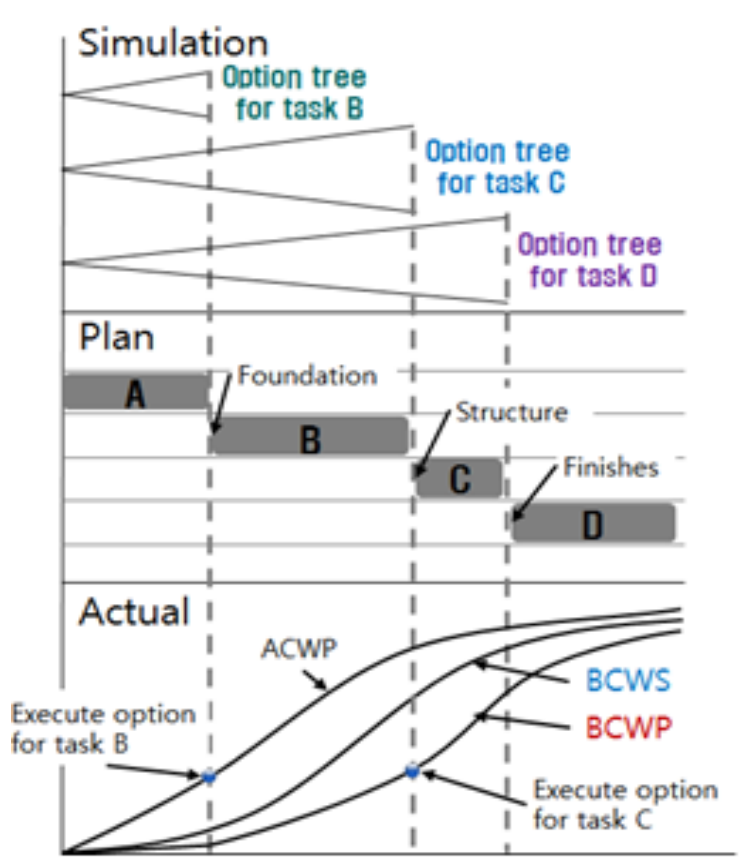

FIGURE IV

LATTICES FOR MAIN CONSTRUCTION METHODS 


\section{CONCLUSIONS}

The technology or method of construction is typically determined during the planning and bidding stages of a project. However, many cases arise where changes in the status of construction during actual work requires a different method to be deployed to ensure that a project's budget and schedule will be its objectives. Existing project delivery methods and decision making processes do not enable project managers to evaluate the value of different construction methods, and also to make appropriate decisions during the actual construction phase.

The research presented in this paper proposed a way to apply real option analysis in valuing the impact of different construction methods. The research also developed a way of linking a binomial lattice model to EVM metrics, enabling project managers a simple but clear way to make decisions on whether to change to a different construction method if it is required to steer a project back on course.

Practically, the research provides a way to quantify and compare the value of different construction methods, and thus can be used to demonstrate the impact of one method over another. In addition, it expands EVM from a somewhat limited monitoring tool to a decision support tool.

\section{ACKNOWLEDGEMENTS}

This research was supported by the Basic Science Research Program through the National Research Foundation of Korea (NRF) and was funded by the Ministry of Education, Science and Technology (2012R1A1A2009327).

Note: This paper was originally published as the conference paper in the ICCEPM 2013 and awarded as one of the best papers. Through a rigorous review process, the paper has been invited to be a special version of JCEPM.

\section{REFERENCES}

[1] M. Amram, N. Kulatilaka, "Real Options: Managing Strategic Investment in an Uncertain World", Harvard Business School Press, Cambridge, MA, 1999.

[2] T. Copeland, V. Antkarov, "Real Options: A Practitioner's Guide", Monitor Group, 2002.

[3] J.C. Cox, A.S. Ross, M. Rubinstein, "Option Pricing: A Simplified Approach", Journal of Financial Economics, vol. 7, no. 3, pp. 229-263, 1979.

[4] D. Ford, D. Lander, J. Voyer, "A real option approach to valuing strategic flexibility in uncertain construction projects", Construction Management and Economics, vol. 20, no.4, pp. 343$51,2002$.

[5] R. Harvey Campbell, "Identifying real options", Duke University, 2002.

[6] Y.-L. Huang, S.-P. Chou, "Valuation of the minimum revenue guarantee and the option to abandon in BOT infrastructure projects", Construction Management and Economics, vol. 24, no. 4, pp. 379-389, 2006.

[7] Z. Tong, K.S. Satheesh, T. Chung-Li, "Highway Development Decision-Making under Uncertainty: A Real Options Approach", Journal of Infrastructure Systems, vol. 10, no. 1, pp. 23-32, 2004.

[8] Q. Cui, M. Bayraktar, M. Hastak, I. Minkarah, "Use of Warranties on Highway Projects: A Real Option Perspective", Journal of
Management in Engineering, vol. 20, no. 3, pp. 118-125, 2004

[9] T. Zhao, C. Tseng, "Valuing Flexibility in Infrastructure Expansion", Journal of Infrastructure Systems, vol. 9, no. 3, pp. 89-97, 2003. 